\title{
El impacto de la emergencia sanitaria por COVID-19 en las relaciones individuales de trabajo
}

\author{
Suárez Jasso, Elsa \\ Universidad Veracruzana, México \\ elsuarez@uv.mx \\ Ostos Cruz, Cecilia Esperanza \\ Cecilia Esperanza \\ ceostos@uv.mx
}

Otero Escobar, Alma Delia

Universidad Veracruzana, México

aotero@uv.mx

Resumen - Está investigación presenta un acercamiento disciplinario a las afectaciones y perspectivas que han impactado a alas relaciones individuales de trabajo dentro de la emergencia sanitaria declarada por la enfermedad denominada COVID-19, poniendo en evidencia cómo las micro, pequeñas y medianas empresas se han visto como las más afectadas; como resultado se presentan posibles soluciones que, desde el ámbito de la legislación laboral se han propuesto y practicado.

Palabras clave - Relación individual de trabajo; Emergencia sanitaria; COVID-19; MiPyMes; Afectaciones; Perspectivas;

Abstract - This research presents a disciplinary approach to the effects and perspectives that have impacted individual work relationships within the health emergency declared by the disease called COVID-19, highlighting how micro, small and medium-sized companies have seen themselves as the most affected; as a result, possible solutions are presented that, from the field of labor legislation, have been proposed and practiced.

Keywords - Individual work relation; health emergency; COVID-19; MiPyMes; affectations; perspectives;

Interconectando Saberes, 2021

ISSN: 2448-8704

(c) EY-NC-ND

\section{INTRODUCCIÓN}

El tema de las afectaciones y perspectivas en las relaciones individuales de trabajo en el contexto de la emergencia sanitaria por COVID-19, tiene como objetivo que se reflexione e identifiquen las consecuencias de una emergencia sanitaria en el ámbito empresarial, tanto para patrones como para trabajadores, tomando conciencia que su actuar en la realidad social puede ser determinante para el cambio sistemático del país.

El análisis del impacto de la emergencia sanitaria por COVID-19 en las relaciones individuales de trabajo, es decir en el ámbito empresarial principalmente de las MiPyMes, inicia con el entendimiento de las relaciones individuales de trabajo, para posteriormente adentrarse a las causales de suspensión de la relación laboral y sus efectos legales, donde se hace referencia dentro de tales causales las emergencias sanitarias,

Fecha de Recepción: 26 de noviembre de 2020

Fecha de Aceptación: 18 de enero de 2021

Fecha de Publicación: 31 de enero de 2021 
haciendo hincapié a la obligación de los patrones, como un deber el acatar en el supuesto jurídico de las hipótesis normativas que hacen referencia a las declaratorias por contingencia sanitaria que hagan las Autoridades al respecto.

Se concluye con las perspectivas o acciones que las Autoridades han tomado para enfrentar la emergencia sanitaria, visualizando que algunas de ellas no han sido idóneas.

\section{RELACIÓN INDIVIDUAL DE TRABAJO}

La relación de trabajo se caracteriza por formalizar el desarrollo de las actividades laborales dentro de una empresa, y podemos identificar dos tipos de relaciones de trabajo:

Tabla 1. Tipos de relación de trabajo

\begin{tabular}{|l|l|l|}
\hline \multicolumn{1}{|c|}{ Tipo de relación } & \multicolumn{1}{|c|}{ Individuales } & \multicolumn{1}{c|}{ Colectivas } \\
\hline $\begin{array}{l}\text { Sujetos de } \\
\text { aplicación }\end{array}$ & $\begin{array}{l}\text { Patrón } \\
\text { Trabajador }\end{array}$ & $\begin{array}{l}\text { Patrón } \\
\text { Sindicato de } \\
\text { trabajadores }\end{array}$ \\
\hline $\begin{array}{l}\text { Instrumento de } \\
\text { formalización }\end{array}$ & $\begin{array}{l}\text { Contrato } \\
\text { Individual de } \\
\text { Trabajo }\end{array}$ & $\begin{array}{l}\text { Contrato } \\
\text { Colectivo de } \\
\text { Trabajo. }\end{array}$ \\
\hline
\end{tabular}

Fuente: Elaboración propia

Una relación de trabajo se ha definido en el artículo 20 de la Ley Federal de Trabajo como cualquiera que sea el acto que le dé origen, es la prestación de un trabajo personal subordinado a una persona, mediante el pago de un salario.
De aquí podemos identificar los elementos práctico-normativos de cualquier relación de trabajo, a saber:

a) Sujetos: los cuales serán dependiendo del tipo de relación de trabajo que se genere.

b) Trabajo: como el objeto del contrato, entendiéndose como toda actividad humana, intelectual o material, independientemente del grado de preparación técnica requerido por cada profesión u oficio, de acuerdo con el artículo 8 de la Ley Federal del Trabajo (LFT).

c) Subordinación: como la cualidad de mando que se ejerce de un individuo a otro (ordenobediencia)

d) Salario: la retribución que debe pagar el patrón al trabajador por su trabajo (artículo 82 LFT).

Conocer los tipos de la relación de trabajo focaliza la investigación, al centrarse en las relaciones individuales y su implicación en las micro, pequeñas y medianas empresas, las cuales son las que formalizan este tipo de relación de trabajo, a través de la celebración del contrato individual de trabajo.

\section{EMERGENCIA SANITARIA DENTRO DE LA LEGISLACIÓN LABORAL}

A manera introductoria a este apartado, tenemos que de acuerdo con el artículo 73 constitucional el Consejo de Salubridad General, que en materia de salud se considera la máxima autoridad administrativa para el tema, publicó el 30 de marzo de 2020 en el Diario Oficial de la Federación (DOF), el Acuerdo declarando emergencia sanitaria por causa de fuerza mayor a 
la epidemia por enfermedad generada por el virus SARS-CoV2 (COVID-19).

Dicho Acuerdo publicado en el DOF estableció las acciones extraordinarias, para atender la emergencia sanitaria generada por el virus SARSCoV2, siguientes:

a) Suspensión inmediata del 30 de marzo al 30 de abril, de actividades no esenciales, para mitigar la dispersión, transmisión, complicaciones y muerte por COVID-19 en el territorio nacional.

b) Se establecieron las actividades consideradas esenciales, quedando al margen de la suspensión.

c) Se exhortó a la población residente en el territorio mexicano, y a la que arribe desde el extranjero y que no labore en actividades esenciales, a cumplir resguardo domiciliario.

d) El resguardo domiciliario corresponsable se aplica de manera estricta a toda persona dentro del círculo considerado vulnerable.

e) El personal esencial de interés público podrá presentarse voluntariamente a trabajar finalizado el periodo de vigencia de las medidas referidas, las autoridades emitirán los lineamientos para un regreso ordenado, escalonado y regionalizado, a las actividades laborales, económicas y sociales.

f) Se posponen hasta nuevo aviso, todos los censos y encuestas a realizarse en el territorio nacional.

g) La aplicación de las medidas será con estricto respeto a los derechos humanos.
Este Acuerdo que se emite en el DOF por el Consejo de Salubridad General, tuvo repercusiones en el ámbito laboral.

Pero, para estar en el mismo contexto y entender el impacto de la declaratoria de emergencia sanitaria, vale la pena recordar que el antecedente legal de una emergencia o contingencia sanitaria en nuestro país data de 2009, cuando se desató la pandemia de la Influenza AH1N1, derivándose en una reforma legislativa en la Ley Federal del Trabajo adicionándose en el año 2012 del artículo 42-Bis, como una exigencia de los Organismos Internacionales (OMS y OIT), para atender situaciones de emergencia donde la salud es un tema primordial en el ámbito mundial. El precepto citado, tuvo y tiene por objeto ampliar las causas de suspensión de las relaciones de trabajo, donde una contingencia sanitaria tiene una disposición normativa de enlace en el artículo 429, fracción IV del mismo ordenamiento legal.

Para ello, es pertinente hacer una transcripción del primer artículo mencionado de la Ley Federal del Trabajo:

Artículo 42 Bis. En los casos en que las autoridades competentes emitan una declaratoria de contingencia sanitaria, conforme a las disposiciones aplicables, que implique la suspensión de las labores, se estará a lo dispuesto por el artículo 429, fracción IV de esta Ley.

Este artículo trajo al debate normativo si el Acuerdo emitido por el Consejo de Salubridad General donde se hacía referencia a "emergencia sanitaria 
por causa de fuerza mayor" correspondía en materia laboral a "declaratoria de contingencia sanitaria" del artículo 42 Bis de la LFT. Ya que de aquí se partía para determinar las medidas laborales a aplicar por parte de las empresas.

Por ello, se procede a definir los términos de emergencia y contingencia sanitaria, para entender si existe diferencia entre ambos:

\section{Tabla 2. Emergencia/Contingencia}

\begin{tabular}{|c|c|}
\hline Emergencia & Contingencia \\
\hline $\begin{array}{l}\text { Situación de peligro o } \\
\text { desastre que requiere una } \\
\text { acción inmediata. }\end{array}$ & Riesgo \\
\hline Emergencia sanitaria & Contingencia sanitaria \\
\hline $\begin{array}{l}\text { Situación de peligro o } \\
\text { desastre en la salud que } \\
\text { requiere una acción } \\
\text { inmediata. }\end{array}$ & Riesgo de la salud. \\
\hline
\end{tabular}

Fuente: Elaboración propia, con base en la Real Academia Española.

Al darse cuenta de las diferencias que marcaba la interpretación de los términos aplicados, las mismas autoridades después de la publicación del Acuerdo, expresaron que se trataba de una situación de "emergencia sanitaria", excluyendo por ende la "contingencia sanitaria". Pero, podemos dilucidar de los conceptos que la contingencia, es anterior a una emergencia, es decir, que la contingencia sanitaria trascendió a un estado de emergencia sanitaria.

Paradójicamente, la interpretación literal de los términos dejaba fuera a las empresas, que mantienen mayormente relaciones individuales de trabajo, a someterse al Acuerdo emitido para suspender inmediatamente e indemnizar, no sucediendo así para el caso de las relaciones colectivas de trabajo que necesitaban el permiso de los Centros de Conciliación y Registro Laboral, para suspender por causa de fuerza mayor y pagar la indemnización. Cabe hacer la acotación que, para las empresas donde prevalecen las relaciones colectivas de trabajo, fue también prácticamente imposible proceder a la suspensión debido a que los Centros de Conciliación cerraron sus puertas cumpliendo con la suspensión establecida en el Acuerdo.

De ello, se desprendió que la autoridad "invitara" a las empresas a que sostuvieran relaciones individuales de trabajo tratando de apegarse a los lineamientos del Acuerdo emitido, y bajo el articulado laboral del 42 Bis, 132 fracción XIX Bis y 429 fracción IV de la LFT.

Analizando el 42 Bis de la LFT, se tendrían que suspender las relaciones de trabajo de forma temporal por el plazo señalado en el Acuerdo, aunado que el artículo 132 fracción XIX Bis da un deber a los patrones de acatar la suspensión, veamos:

Artículo 132.- Son obligaciones de los patrones:

XIX Bis. Cumplir con las disposiciones que en caso de emergencia sanitaria fije la autoridad competente, así como proporcionar a sus trabajadores los elementos que señale dicha autoridad, para prevenir enfermedades en caso de declaratoria de contingencia sanitaria; ... 
Este artículo viene a complementar la hipótesis legal del artículo 42 Bis, dando la posibilidad de suspender labores como mandato de la autoridad competente.

Respecto a la indemnización, el artículo 429 de la ley multicitada, en su fracción IV establece:

“...el patrón no requerirá aprobación o autorización del Tribunal y estará obligado a pagar a sus trabajadores una indemnización equivalente a un día de salario mínimo general vigente, por cada día que dure la suspensión, sin que pueda exceder de un mes".

De dicho precepto se desprende la obligación del patrón de pagar una indemnización a sus trabajadores de un mes, de acuerdo con el salario mínimo vigente. Actualmente el salario mínimo vigente (2020) es de \$123.22 multiplicándolo por 30 días de trabajo da como resultado $\$ 3,696.60$ de indemnización por contingencia sanitaria.

Esta es la cantidad que por indemnización debían pagar las empresas a sus empleados el tiempo que duraba la suspensión emitida por la contingencia, donde cumplir con ello resultaba económicamente imposible para las empresas que se mantienen prácticamente al día.

Ahora bien, se plantea la duda de ¿qué pasaría después de la suspensión marcada por el Acuerdo?

Se tendrían que reanudar las actividades después de la suspensión derivada de la emergencia sanitaria, y los empresarios deberían garantizar las mismas condiciones de trabajo a sus trabajadores que tenían antes de la suspensión. Si el patrón no reanudara las actividades, el trabajador tendría derecho a la indemnización establecida en el artículo 50 de la LFT. Por ejemplo, en el caso de una relación individual de trabajo por tiempo indeterminado, la indemnización comprendería:

- 20 días de salario del trabajador por cada año de servicio prestado

- 12 días de salario del trabajador por prima de antigüedad

- Tres meses de salario, y

- partes proporcionales de vacaciones, prima vacacional y aguinaldo

Derivado de la interpretación sistemática de los preceptos legales, podríamos concluir que la emergencia sanitaria del Acuerdo es equiparable a una contingencia sanitaria de la LFT, ambos términos no son contradictorios entre sí, es decir que no se contraponen, sino únicamente la emergencia implica haber ido más allá de la contingencia, por ser una realidad y no una posibilidad, y que derivado de ello se encuadraría en el artículo 42 Bis y como consecuencia lógica en la fracción IV del artículo 429, ambos de la LFT.

Del análisis legal, para los trabajadores, en especial aquellos que participaban de una relación individual de trabajo, era tranquilizador contar con una indemnización durante un mes que duraba la suspensión de labores, pero para la gran mayoría de las empresas, en especial las micro, pequeñas y medianas, pagar estas indemnizaciones cuando 
no estaban percibiendo ganancias, fue gravoso, y en muchos casos, imposible.

La poca claridad del mencionado Acuerdo e interpretación legal - laboral, ha llevado a los empresarios (patrones) al limbo legal y financiero.

\section{AfECTACIONES LABORALES EN EL CONTEXTO DE LA EMERGENCIA SANITARIA COVID-19}

Ahora bien, la pandemia por COVID-19 ha devastado el mundo del trabajo, dejando en evidencia la extrema vulnerabilidad de muchas personas y empresas.

Según estimaciones de la OIT en su documento "La COVID-19 y el mundo del trabajo" (2020 p.2), el número de centros de trabajo que han cerrado en todo el mundo en respuesta por COVID-19 ha reducido en un 10,7 por ciento el total de horas trabajadas en el segundo trimestre de este año. Esto ha provocado la pérdida de 305 millones de empleos. Siendo el continente americano la región más afectada.

En el ámbito internacional del trabajo, la contingencia sanitaria ha golpeado duramente a las personas más desfavorecidas, incrementando las desigualdades. De acuerdo con los datos de la OIT del documento citado, en la economía informal, 6 de cada 10 trabajadores viven del día a día. De estos 2000 millones de trabajadores, 1600 millones ven amenazados sus medios de subsistencia, dado que en la economía informal se redujo un $60 \%$ su ingreso medio, aumentando el índice de la pobreza.

Para el caso de las relaciones individuales de trabajo y las afectaciones de la emergencia por COVID-19, las mujeres han estado sobrerrepresentadas en los sectores más afectados, como el sector de los servicios y el de la salud, donde según nuestra STPS representan el $70 \%$ del personal. Es decir que, hablando de género, las mujeres trabajadoras han sido las más afectadas, al prácticamente perder su empleo, al ser cabezas de familia, madres 0 tener dependientes económicos en edad económicamente inactiva, el cierre de las escuelas o de las guarderías, han provocado que decidan apartarse "voluntariamente" de su trabajo, para desempeñar roles atribuidos de forma ancestral.

Se suman a los afectados los jóvenes que tenían un trabajo antes de la contingencia sanitaria, la OIT ha señalado que 1 de cada 6 ha perdido su empleo, mientras que a los otros se les han reducido las horas de trabajo en un 23 por ciento y a su vez su salario, números que se reproducen a nivel nacional.

Con relación a las micro, pequeñas y medianas empresas, las cuales materializan las relaciones individuales de trabajo, la OIT en el documento ya mencionado, ha señalado:

Las empresas, en particular las micro y las pequeñas y medianas empresas, con pocas reservas para subsistir incluso durante breves períodos de inactividad, se encuentran ante una 
gran incertidumbre, en el mejor de los casos. En los cuatro sectores más duramente golpeados sólo por la pandemia - el comercio al por mayor y al por menor y la reparación de vehículos automóviles; la industria manufacturera, los servicios de hotelería y restauración, y las actividades inmobiliarias, comerciales y administrativas - por lo menos 436 millones de empresas corren un gran riesgo de quedar desestabilizadas. (2020, p.3)

La primera afectación laboral para las micro, pequeñas y medianas empresas dentro del país fue determinar, si la mera suspensión de las relaciones individuales de trabajo, implicaban pagar la indemnización establecida en el artículo 429 fracción IV de la LFT.

La mayoría de los empleadores negaron el pago de la indemnización por no tener los recursos para ello, ya que la venta era diaria y al final el supuesto legal no los obligaba al no ser una contingencia sanitaria, sino una emergencia sanitaria según el Acuerdo. No obstante, se comprometieron ante la Autoridad Laboral a preservar, en medida de lo posible, la fuente de trabajo y buscar convenios para el pago parcial de salarios.

Muchos trabajadores fueron despedidos después del anuncio de la suspensión de labores, en especial aquellos cuya relación de trabajo era individual, para lo cual la Procuraduría Federal de la Defensa del Trabajo (PROFEDET) manifestó que tal situación se consideraría despido injustificado, pudiéndose acudir ante ellos para su defensa de manera gratuita.
Otra decisión que tomaron los empresarios fue otorgar vacaciones escalonadas para sus trabajadores, con la finalidad de tener mano de obra durante la pandemia, situación que convino al no perder la fuente de empleo, sin embargo, la contingencia se ha ido alargando y los períodos escalonados vacacionales en la mayoría de las empresas que los aplicaron se han ido agotando, tomando decisiones de concluir la relación laboral.

Algunos de los patrones que dieron por concluida la relación de trabajo con sus trabajadores, optaron por recontratar a sus trabajadores o contratar nuevos, bajo las nuevas modalidades de duración de trabajo: por período a prueba y para capacitación inicial, terminando con las mismas después de los períodos establecidos en la LFT, 30 días y 3 meses respectivamente, sin generar el principio básico de estabilidad laboral.

Otra situación fue el desconocimiento de muchas micro y pequeñas empresas establecidas de si debían suspender o no sus actividades por la contingencia sanitaria, de acuerdo con su giro o actividad económica.

Algunos patrones aprovecharon para sostener sus empresas a través del pago del salario mínimo, durante el lapso que dure la emergencia sanitaria, afectando el poder adquisitivo y salario digno de muchos trabajadores, sin embargo, no perdieron su trabajo. 
A ello se suma el hecho de que algunos trabajadores que prestaban sus servicios durante la pandemia se enfermaron de COVID-19 y el Seguro Social no sabía que tratamiento administrativo aplicar ante la enfermedad, al no encontrarse en el cuadro básico de enfermedades por riesgo de trabajo, sin abordar el tema de fallecimiento por COVID19 y sus consecuencias.

Según datos de la Confederación de Cámaras Nacionales de Comercio, Servicios y Turismo (CONCANACO), el 65\% de los comercios de todo el país han tenido que cerrar "temporalmente", sin saber hasta este momento el índice de los que van a reaperturar después de la contingencia, como ejemplo señalan que el $80 \%$ de los hoteles están en inactividad total cayendo con ese mismo margen sus ganancias, su afirmación es categórica del riesgo en el que se encuentran miles de empleos y la supervivencia de las empresas, en especial las micro, pequeñas y medianas, las cuales son las que se caracterizan por concretar relaciones individuales.

El presidente de la CONCANACO, en entrevista para el periódico El Universal el 31/03/2020, sostuvo que:

"Con esta emergencia anunciada para los próximos 30 días, que obliga a los establecimientos a cerrar, muchas empresas, principalmente las micro y pequeñas, tendrán consecuencias económicas graves, porque no generarán recursos para seguir sosteniendo el pago de nómina como pide el gobierno federal, sin tener ingresos".
Figura 1. Algunas afectaciones laborales ante la contingencia sanitaria por COVID 19

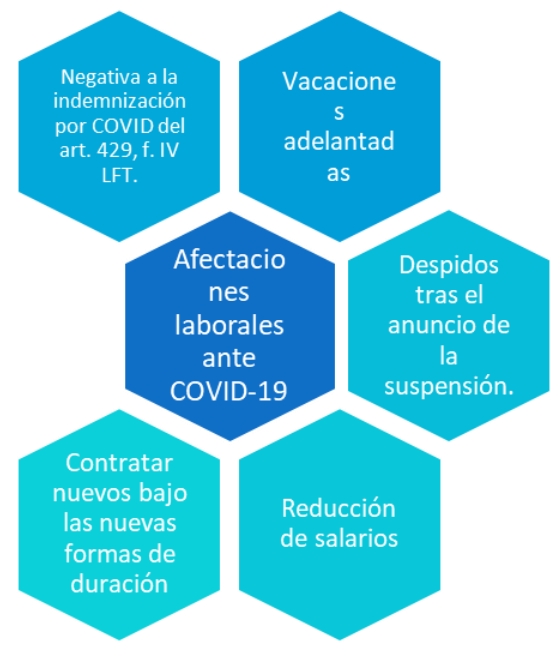

Fuente: Elaboración propia.

Como podemos apreciar, todas estas afectaciones en las relaciones individuales de trabajo, han generado situaciones de facto, no encuadradas de derecho, es decir, la Autoridad en materia laboral, no ha emitido cifras oficiales de desempleo a partir de la suspensión por emergencia sanitaria, ni tampoco el número de empresas que la misma contingencia ha obligado a cerrar o las pérdidas percibidas, ni cuantas de ellas han atendido las recomendaciones laborales.

\section{PeRspectivas laborales EN EL CONTEXTO DE LA EMERGENCIA SANITARIA COVID-19}

En lo que se ha denominado "la nueva normalidad" se ha visualizado el retorno de distintas actividades económicas dependiendo del semáforo de la pandemia, siendo el ámbito laboral un eslabón que se dejó de lado ante las consecuencias y las diversas interpretaciones sistemáticas que dejaban a empresarios y trabajadores en el limbo. 
Las relaciones individuales de trabajo tienen el gran reto de subsistir lo que dure la emergencia sanitaria por COVID-19, las micro, pequeñas y medianas empresas sostienen gran parte de la economía del país, ya que otorgan nueve de cada 10 empleos en nuestro país. Ello nos lleva a reflexionar si durante la pandemia, ¿podrán estas empresas pagar la nómina de sus trabajadores, sin recibir los ingresos habituales?

La evidente respuesta a esta pregunta, ante la imposibilidad de cumplir con el pago de la nómina o de la indemnización por ley señalada en la LFT, ha llevado a que la STPS recomiende o sugiera realizar convenios con sus trabajadores, individual o colectivamente, una modificación en las condiciones de trabajo, bajo la premisa de que las relaciones de trabajo obligan a lo expresamente pactado y a las consecuencias de conformidad con las normas de trabajo, a la buena fe y a la equidad (según artículos 31 y 33, LFT). Se trata de una modificación pactada de condiciones laborales, que permita a los trabajadores percibir ingresos y a la empresa sobrevivir, de acuerdo con sus posibilidades, siendo ratificado ante los Centros de Conciliación o al Tribunal según corresponda, que lo aprobará siempre que no contenga la renuncia de los derechos de los trabajadores.

Dentro de las perspectivas que se visualizan con respecto a los centros de trabajo o empresas que ya deban retornar a sus actividades de acuerdo al semáforo de la emergencia sanitaria, es relevante que se tomen las medidas de salubridad correspondientes descritas en los "Lineamientos Técnicos de Seguridad Sanitaria en el Entorno Laboral" emitido en coordinación entre la Secretaría de Salud, la Secretaría de Economía, y la Secretaría de Trabajo y Previsión Social, donde se pone de manifiesto lo siguiente:

a) Estrategias de control que tienen como fin contener la diseminación del COVID-19, implementándose en todos los centros de trabajo, sin importar el tipo de relación de trabajo, tipo de empresa, su actividad o el nivel de alerta de la localidad en la que se encuentren:

\section{Tabla 3. Estrategias de control para promover la salud}

\section{Promoción de la salud}

Proporcionar información general sobre el SARS-CoV-2, mecanismos de contagio, síntomas que ocasiona y maneras de prevenir la infección.

Lavarse las manos con agua y jabón frecuentemente o bien, usar soluciones a base de alcohol gel al $70 \%$.

Práctica de la etiqueta respiratoria: cubrirse la nariz y boca al toser o estornudar, con un pañuelo desechable o el ángulo interno del brazo.

No escupir.

No tocarse la cara.

Limpiar y desinfectar superficies y objetos de uso común dentro del área de trabajo.

Mantener una sana distancia

Fuente: Elaboración propia

b) Medidas de Protección en Salud (Seguridad e Higiene en el Trabajo), dividiéndose en cuatro vertientes: 
Tabla 4. Medidas de protección en la salud para garantizar la seguridad e higiene en el trabajo

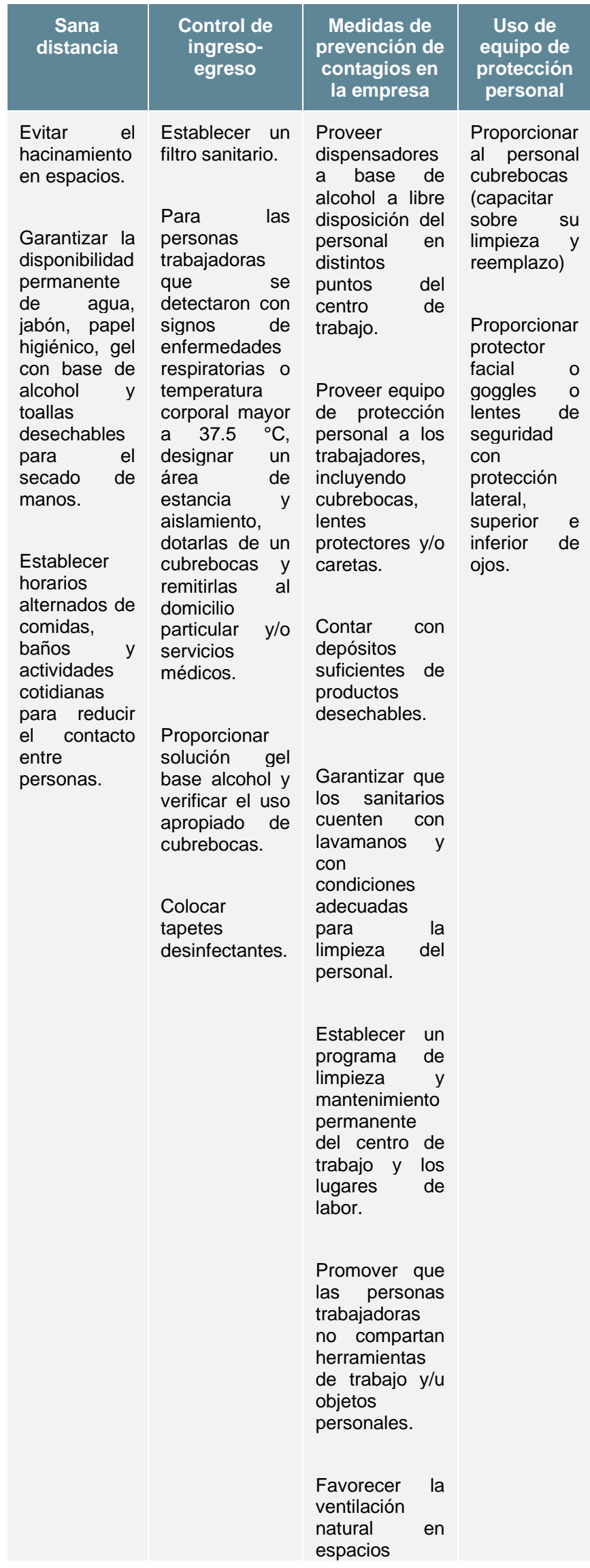

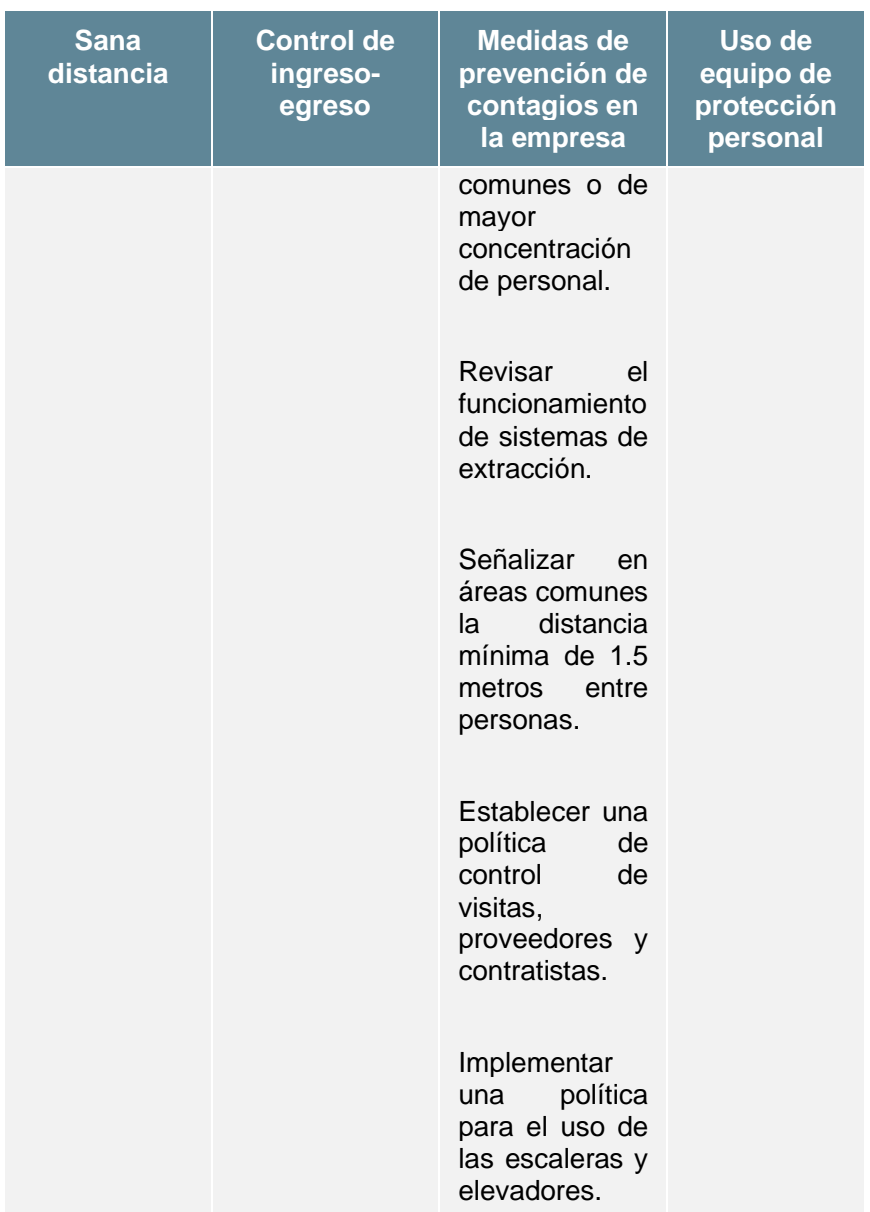

Fuente: Elaboración propia

Aunado a lo anterior, los Lineamientos recomiendan a las empresas un Plan para el retorno al trabajo ante COVID-19, el cual comprende una secuencia de acciones que los centros de trabajo deberán implementar para el regreso a las actividades, reduciendo el riesgo de contagio por COVID-19 y las afectaciones que la epidemia pudiera causar.

Dicho Plan incluye establecer un Protocolo de Seguridad Sanitaria dentro de las empresas, con los siguientes pasos: 
Figura 2. Plan para establecer el Protocolo de Seguridad Sanitaria
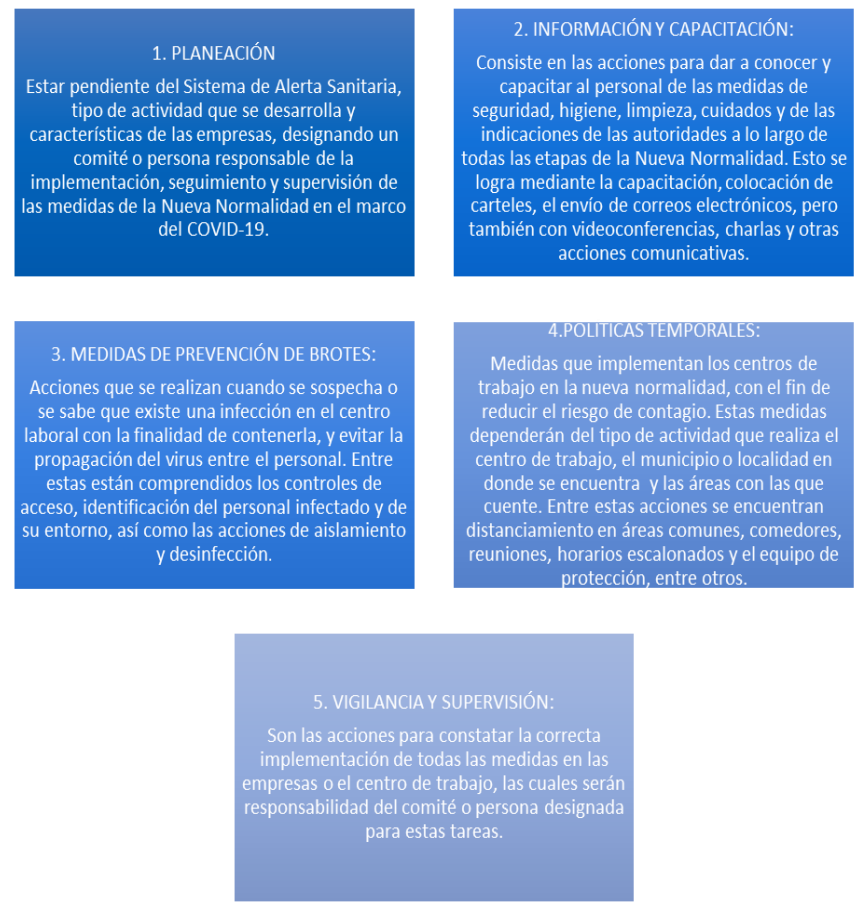

Fuente: Elaboración propia.

Dicho Protocolo de Seguridad será obligación de las pequeñas y medianas empresas de implementarlo, incluso podrá ser objeto de registro ante la autoridad laboral; para su elaboración, también podrán apoyarse de las asesorías que de forma gratuita está dando la misma autoridad.

Se suma a las recomendaciones para todas las empresas la protección a los grupos considerados vulnerables, priorizando en ellos el trabajo en casa o teletrabajo, tema también a regular legislativamente dentro de la LFT.

Las empresas han manifestado su inquietud respecto a que se han tomado muchas acciones o medidas para la prevención de la enfermedad, pero no respecto a los procedimientos ante los trabajadores confirmados por COVID-19, para ello debe tomarse en cuenta que es una enfermedad general y tendría que seguirse el procedimiento para tramitar un certificado de incapacidad emitido por el Instituto Mexicano del Seguro Social, sin embargo, esto ha sido más complicado por la gravedad de la enfermedad. En fechas recientes el IMSS ingreso al cuadro de enfermedades por riesgo de trabajo a COVID-19, teniendo esto implicaciones en el ámbito de la seguridad social.

En materia laboral, las sanciones a aplicar a los patrones que no acaten la suspensión por contingencia sanitaria se encuentran descritas en el artículo 994 de la LFT, donde se establece que se impondrá una multa de 50 a 1500 Unidades de Medida y Actualización (UMAS), y en caso que el patrón no observe la instalación de las normas de seguridad e higiene en sus establecimientos o las medidas que fijen las leyes para prevenir los riesgos de trabajo, el mismo artículo fracción $\mathrm{V}$ menciona una multa que va desde 250 a 5000 UMAS.

Finalmente, hay que tener presente que el incumplimiento de las prácticas y medidas ordenadas para mitigar el contagio del COVID-19, puede acarrear responsabilidad penal y administrativa, tanto para las empresas como para sus administradores y apoderados, por el delito de peligro de contagio, de conformidad con el Código Nacional de Procedimientos Penales, y los Códigos Penales de las entidades, siendo para las micro, pequeñas y medianas empresas difícil la situación 
de aplicar todas las medidas sanitarias que implican una erogación monetaria y a su vez pagar sanciones administrativas o penales, ello sin tomar en cuenta el pago de la nómina a sus trabajadores.

Aunado a los convenios laborales referidos en el numeral 33 de la LFT y las medidas de salud para un retorno asistido en las empresas, una legislación más flexible que incluya el teletrabajo, claridad en las sanciones que puede ser objeto un empresario ante el incumplimiento de las medidas sanitarias aplicables en materia laboral, resulta esencial que el gobierno provea de apoyos sociales a los trabajadores, como también de estímulos fiscales y laborales a las empresas, en especial a aquellas que materializan las relaciones individuales de trabajo, es decir, las micro, pequeñas y medianas empresas.

\section{CONCLUSIONES}

La OIT ha recomendado los 4 grandes pilares a seguir frente a la pandemia COVI-19, los cuales los países miembros tendrán que seguir.

Es aquí donde se visualiza de forma clara cómo se requieren de diversas profesiones y recursos para combatir la emergencia sanitaria. El fortalecimiento de las relaciones individuales de trabajo es imperante, ya que en materia laboral y de salud han sido de los más sacudidos y sucumbidos.
Figura 3. La COVID-19 y el mundo del trabajo.

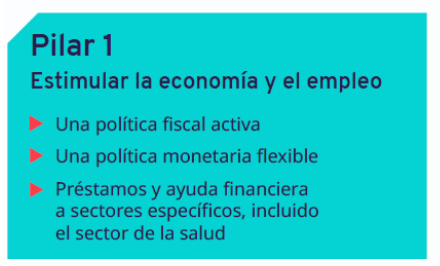

\section{Pilar 3}

Proteger a los trabajadores en el lugar de trabajo

$>$ Reforzar las medidas de SST

Adaptar las modalidades de trabajo

(por ejemplo, el teletrabajo)

Prevenir la discriminación y la exclusión

Permitir el acceso a la sanidad para todos

Ampliar el recurso a una licencia

remunerada

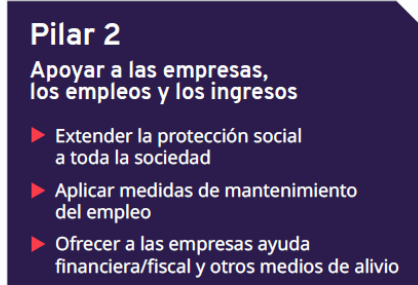

\section{Pilar 4}

Buscar soluciones mediante

el diálogo social

Fortalecer la capacidad y la resiliencia

y de trabajadores

Fortale

Fortalecer el diálogo social, la negociación

colectiva y las instituciones y
de las relaciones laborales

Fuente: Observatorio de la OIT, 2020.

En épocas de crisis como la presente, es fundamental proteger tanto el ingreso de los trabajadores, como la fuente de empleo y los puestos de trabajo. Así, que hay adoptar soluciones que permitan un equilibrio entre todas estas aristas.

Las empresas, sus patrones y trabajadores, deberán conocer e identificar una situación de emergencia o contingencia sanitaria que cambie el panorama de la misma empresa donde emprenden como socio o como empleados. Son ellos los actores, dependiendo de la trinchera donde se desarrollen, a los que les corresponde realizar las guías para elaborar y ejecutar los protocolos de seguridad sanitarios emitidos por las autoridades, hacer el cálculo de la indemnización por la declaratoria de contingencia sanitaria y pagarla, dar continuidad a los trámites de incapacidad por COVID-19, elaborar los convenios internos realizados entre patrones y trabajadores para la modificación de las condiciones que puedan preservar la fuente de trabajo, entre otras más. 


\section{REFERENCIAS}

Bermúdez, M., (2002) Derecho del trabajo. México, Oxford.

Davalos, J., (2014). Derecho del trabajo. México, Porrúa.

Diario Oficial de la Federación (2019). Ley Federal del Trabajo México. Consultada el 20 de octubre de 2020. Disponible en:

https://www.dof.gob.mx/nota detalle.php?co digo $=5559130 \&$ fecha $=01 \% 2 \mathrm{~F} 05 \% 2 \mathrm{~F} 2019$

Diario Oficial de la Federación (2020). Constitución Política de los Estados Unidos Mexicanos. México.

El Universal (2020). Cierra 65\% de comercios en México por Covid-19; en riesgo miles de empleos, advierten. Consultada el 10 de septiembre de 2020. Disponible en: https://www.eluniversal.com.mx/cartera/coro navirus-cierra-65-de-comercios-en-mexicopor-covid-19-en-riesgo-miles-de-empleos

Garrido, A., (2013). Derecho Individual del trabajo. México, Oxford.

Gobierno de México (2020). Lineamientos Técnicos de Seguridad Sanitaria en el Entorno Laboral, Consultado el 20 de octubre de 2020. Disponible en:

http://nuevanormalidad.gob.mx/

Kurczyn, P., Reynoso, C., \& Sánchez, A. (2007). Derecho laboral globalizado. México: Instituto de Investigaciones Jurídicas, Universidad Nacional Autónoma de México. López Ayón, S., \& González, M. D. R. (2000). Transiciones y diseños institucionales. México, UNAM, Instituto de Investigaciones Jurídicas, reimpresión.

Organización Internacional del Trabajo (2020). El COVID-19 y el mundo del trabajo:

Repercusiones y respuestas. Consultada el 12 de septiembre de 2020. Disponible en:

https://www.ilo.org/wcmsp5/groups/public/--dgreports/---

dcomm/documents/briefingnote/wcms 7391 58.pdf

Organización Internacional del Trabajo (2020). Nota Conceptual. Cumbre mundial OIT y COVID-19. Consultada el 12 de septiembre de 2020. Disponible en:

https://www.ilo.org/wcmsp5/groups/public/@ dgreports/@dcomm/documents/meetingdocu ment/wcms 747938.pdf
Organización Internacional del Trabajo (2020). Observatorio de la OIT: La COVID-19 y el mundo del trabajo. Quinta edición, Estimaciones actualizadas y análisis.

Consultada el 12 de septiembre de 2020. Disponible en:

https://www.ilo.org/wcmsp5/groups/public/@ dgreports/@dcomm/documents/briefingnote/ wcms 749470.pdf

Organización Internacional del Trabajo (2020). Observatorio de la OIT: La COVID-19 y el mundo del trabajo. 1a edición. Consultada el 12 de septiembre de 2020. Disponible en: https://www.ilo.org/global/about-theilo/WCMS 739158/lang--es/index.htm

Soto, J. (2014). Teoría General del Derecho del Trabajo. México. Trillas. 